from the sediments "changing into granite in the ultimate expression of metamorphism."

It would be unfair, however, to judge the author's powers of observation from this or by his more startling propositions, such as that of the reconstitution of sand-grains on p. I 40 . The fact that he has seen so much throughout South Africa, in a country laid bare by nature for the geologist, entitles him to a serious hearing. The emphasis that he lays on the descent of ore-material from the surface (p. in), and on the ascent of calcium carbonate from below, recalls at once the tropical rains, and the "pans" upon the desiccating surface. But surely, as Mr. Mennell has lately pointed out in his "Petrology," there is abundant evidence of the accumulation of iron-ores under African conditions at the surface. The whole siliceous crust, however, according to Prof. Schwarz, is a residue from the leaching-out and downsinking of iron and magnesium from the primitive meteoritic matter. The silica was first set free from this matter in a colloidal form which consolidated as

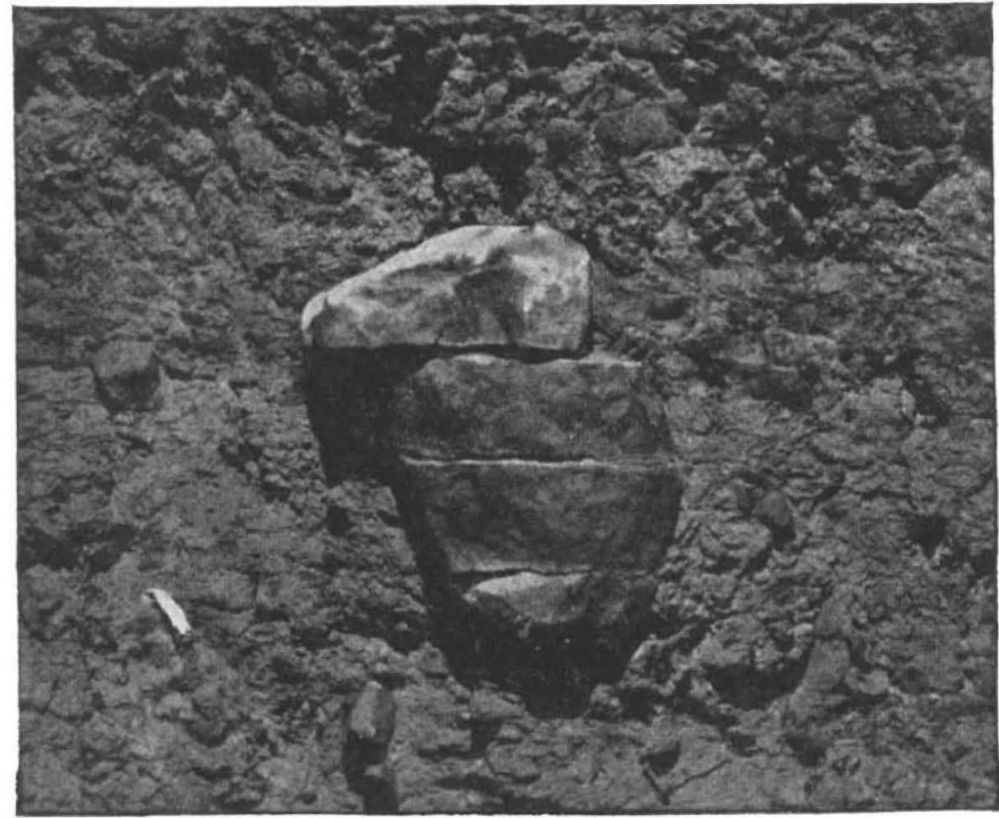

Buulder in Dwyka Conglomerate, Prieska, illustrating lateral flow in rocks under pressure. From "Causal Geology."

chert. Quartz arose only by metamorphic action in the depths (p. 39). When we are told that chert is not crystalline, and when we reflect on the quartz deposited in cavities from solution, as is the case in limestones which retain all their fossils, we cannot help thinking that our author's earlier studies have been temporarilv overcast by a cloud of planetesimals. The careless writing of some sentences suggests that the work has been pushed forward with something of the heat of a new gospel. The word "meteorite" is thus missing in the middle of p. 10; cubes of salt are said to be present (p. 57) in the "bubbles in granitic quartz" ; to most field-workers the Archæan masses (p. 69) cannot seem "characterised by the enormous development of limestone"; when carbon dioxide is included in an analysis of the air, the omission of argon and its allies can hardly be excused (p. 93) by their "minute proportions"; Fig. A, a lunar area, opposite p. 22, should surely be inverted to agree with its description; and, to come to smaller matters, grammar is imperfect on pp. 3, I3I, I45, and 200. NO. 2 I 35 , VOL. 84]
Yet we again and again respect Prof. Schwarz's grasp of geological literature, writing as he does in a small South African town, and his preface shows that he is still to be ranked among the inquirers, and not as the apostle of a dogma. Probably we also have been the gainers, if, after reading his well-printed and well-illustrated book, we feel that we know less than before concerning the constitution of the globe.

Grenville A. J. Cole.

\section{THE BRITISH SECTION OF THE BRUSSELS EXHIBITION.}

THE importance of a Government department to deal with exhibitions could not have been better exemplified than when the King of the Belgians opened the new British section of the Brussels Exhibition on September I9. Exactly five weeks previously the section which had cost so much in thought, time, and money was reduced to a smoking mass of ruins. For a moment everyone was stunned by the extent of the loss, but within a few hours it had been determined to rebuild the section provided the reply received from previous exhibitors was satisfactory. 'The replies were not only satisfactory, but almost overwhelming; in fact, more space was applied for than the Commission had at its disposal.

But the rebuilding of the section was only rendered possible by the Belgian Commission placing at the disposal of the British organisers the Salle des Fêtes. This building was originally used for holding large congresses and meetings, and had a platform and a sloping auditorium, the side alleys being divided up into reception and cloak rooms. All the internal fittings of this building have been removed, and it has been divided up into courts in a most artistic fashion, the various courts radiating out from a central transept.

The space of the original building was I50,600 square feet; the present space is only 35,500 feet; but this fact made it difficult rather than easy to design and fit up the new section, owing to the large number of exhibitors who desired space. How rare is it for an exhibition to be ready for the opening day, even after months have been spent in collecting the exhibits! But although the work was enormous, the new section arose from the ashes in the space of five weeks, and the whole exhibit, with the exception of one or two cases, was absolutely finished when the King of the Belgians opened it. Not only was the exhibit finished, but the new catalogue, "Catalogue Officiel de la nouvelle Section Britannique," was ready on the same day for distribution. Without the machinery of the committees organised by the Royal Commission of the Board of Trade it would, however, hardly have been possible to have accomplished this feat.

In declaring the new section open, and replying to Sir Arthur Harding, the King said: "Your Exce]lency has associated the British and Belgian people in the eulogy which vou have made in such happy terms of the work of repairing the disaster caused by the fire. Certainly the Belgians have displayed in that work their fine qualities of courage and perseverance which no misfortune can daunt, and I congratulate them upon it highly. But what shall I say 
of the English--of the Government as of the exhibitors -who, in reconstructing in the space of a few weeks a section as beautiful and interesting as anyone could possibly wish for, have once more shown of what that unconquerable tenacity, the characteristic of the British Empire, is capable. I find no words to express to Your Excellency my admiration and my gratitude."

One of the most interesting exhibits is that of the Thermal Syndicate. The articles are manufactured at the high temperature of the electric arc, and it is of particular interest to notice that even the intense heat of the conflagration had no effect upon the silica ware. In the new section, tubes and pipes which had been through the fire are exhibited alongside of articles freshly manufactured. These tubes have glass fused to them, but, except for slight discoloration, are absolutely uninjured by the ordeal through which they have passed.

Although Messrs. Johnson and Matthey have not been able to exhibit again, it should be mentioned that the transparent silica shown by them in the original section was also in no wise injured by the heat, although much of it was broken by the falling débris. The writer found pieces of platinum exhibited by the same firm absolutely embedded in fused glass, which gives a good idea of the intense heat to which everything in the burning building was subjected.

Is showing the resource of energy of some of the exhibitors, mention should be made of the pottery exhibit of Mr. Bernard Moore. A large vase is shown which has been designed and manufactured since the fire and bears a commemorative design-a phæenix risingr fron the flames with the motto Quod ignis debit incendium abstulit. The Pilkington Tile and Pottery Co. also shows a commemorative vase. This is of particular interest, because it shows a new lustre which has not been discovered more than three months.

The International Salt Co., I.td., shows salt purified br a new process. The salt is fused and air blown through it, the impurities separate out, and the pure salt is run off. Whether. this process will be able to compete against the older process remains to be seen, but at least it is interesting.

Owing to the exigencies of time and of space, it has not been found possible to instal again completely the very fine display of scientific instruments and of chemicil products which was shown in the original section, but the chemical court makes quite a good display. The section, as a whole, is a splendid example of what can be done by organisation and the courage which knows no defeat.

It should be mentioned in closing that the advances due to recent science have been found to be of the utmost value in the cutting and removal of the tangled mass of irnn-work which is all that remains of the burnt-rut parts of the exhibition. The cutting of even thick girders is done entirely by burning with the oxyhydrosen flame, and it is extremely interesting to notice how rapidly it is possible to work by means of this method.

\section{F. Mollwo Perkin.}

\section{M.ITHE.MATICS IN AUSTRIA.}

$A S$ the result of an educational conference, conA vened at Vienna in 1908 , changes of considerable importance have been made in the curriculum of the secondary schools of Austria. At the instance of the Board of Fducation, the mathematical syllabus issued in roog for the Austrian Gymnasien has been translated into English, and it deserves the thoughtful consideration of all those who are interested in the efficiency of our own educational system. It comes at an opportune moment and forms a useful contribution to all the discussions and experimental investigations of the last few vears, which should provide a sound foundation for the work of the International Commission on Mathematical Teaching, which will report to the congress at Cambridge in Igra. We do not propose to examine this pamphlet in detail, but it may be useful to note some of its salient features.

Although in recent vears the theoretical has been replaced by the practical in our secondary schools to a degree which many have considered dangerous, it is clear that far more drastic measures have been adopted by the Austrian authorities. The course of arithmetic is limited to multiplication and division of decimals, contracted methods, proportion and interest. There are few who will not admit that the time spent on mixtures, discount, stocks, and the various other specialised arithmetical problems, which occupy so large a space in our text-books, might be employed to far greater advantase. At present only a small proportion of boys ever obtain a working knowledge of the elements of trigonometry and the calculus. Reform in this direction is badly needed, but it is almost impossible for changes to be made in the school curriculum so long as the various examining bodies, and in particular the Oxford and Cambridge joint board and the Civil Service Commissioners, continue to require a standard in arithmetic, which can only be attained by a large expenditure of time. There is much to be said for omitting altogether the arithmetic paper from these examinations, but, if this should be regarded as too extreme a measure, we are profoundly convinced of the desirability of restricting it to simple questions on the laws of the subject; the time thus saved would be devoted to numerical trigronometry, and consequently it would be reasonable to expect from candidates for such examinations as the leaving certificate or army qualifying an elementary practical knowledge of trigonometry. It would be difficult to exaggerate the benefits which would result from such a change as this, and we do not doubt that it will come, although not in the near future.

The next feature of interest is the importance which is attached to the idea of functionality.

"The notion of Function is recognised as the idea which differentiates higher from elementary mathematics, and a full erasp of it is held to be the proper aim of school teaching . . . the habit of looking at variable quantities as varying continuously and in obedience to laii is to be fostered from the beginning."

Experience shows how slow is the growth of appreciation of this conception, but the sphere of its operation is so extensive and its application so stimulating that it well repars the effort required. If the craphical work in algebra is not designed to illustrate this principle, it is reduced to a valueless mechanical operation.

The last noteworthy variation is the combination of plane and solid geometry throughout. The cultivation of the power of thinking in three dimensions receives far more attention on the Continent than in England. Many even of those who win mathematical scholarships at our universities have no knowledge of the rudiments of practical solid geometry. There are signs, however, of change in this direction, and the value of an elementary course on plan and elevation of simple solids is being gradually realised.

Enough has been said to show that the guiding principles of this svllabus are progressive and eminently practical, and the Board of Education have done well to render it accessible.

NO. 2135 , VOL. 84$]$ 